\title{
Dextran-coated superparamagnetic iron oxide nanoparticles activate the MAPK pathway in human primary monocyte cells
}

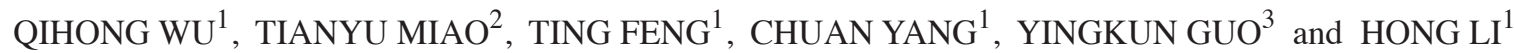 \\ ${ }^{1}$ Key Laboratory of Obstetrics and Gynecology and Pediatric Disease and Birth Defects of Ministry of Education, \\ West China Second University Hospital, Sichuan University; ${ }^{2}$ Department of Vascular Surgery, \\ West China Hospital; ${ }^{3}$ Department of Radiology, West China Second University Hospital, \\ Sichuan University, Chengdu, Sichuan 610041, P.R. China
}

Received July 9, 2017; Accepted April 25, 2018

DOI: $10.3892 / \mathrm{mmr} .2018 .8972$

\begin{abstract}
With the increase in applications of superparamagnetic iron oxide nanoparticles (SPIONs) in biomedicine, it is essential to investigate the bio-security of these nanoparticles, especially with respect to the human immune system. In the present study, the biological effects of dextran-coated superparamagnetic iron oxide nanoparticles (Dex-SPIONs) on human primary monocyte cells were evaluated. The results of the present study demonstrated that Dex-SPIONs can be identified in phagosomes or freed in the cytoplasm and did not affect cell viability or induce apoptosis. Notably, there were certain bulky vacuoles and a number of pseudopodia from the cell membrane, suggesting potential activation of human monocyte cells. In addition, the expression levels of pro-inflammatory cytokines interleukin (IL)- $1 \beta$ and tumor necrosis factor (TNF)- $\alpha$ were also increased following treatment with Dex-SPIONs. Simultaneously, the phosphorylation levels of mitogen-activated protein kinase (MAPK) p38, c-Jun N-terminal kinase 1 and extracellular signal regulated kinase were markedly enhanced following nanoparticle exposure and MAPK inhibitors could abate the production of IL-1 $\beta$ and TNF- $\alpha$. The results of the present study demonstrated that Dex-SPIONs could activate human monocyte cells and that activation of MAPK pathway may be involved in these effects.
\end{abstract}

\section{Introduction}

Nanoparticles (NPs) have been widely applied in the field of healthcare owing to their unique physicochemical

Correspondence to: Professor Hong Li, Key Laboratory of Obstetrics and Gynecology and Pediatric Disease and Birth Defects of Ministry of Education, West China Second University Hospital, Sichuan University, 20 South Renmin Road, Chengdu, Sichuan 610041, P.R. China

E-mail: lhong3985@163.com

Key words: monocytes, mitogen-activated protein kinase, nanoparticles, pro-inflammatory cytokines characteristics including large surface-to-volume ratio and small size $(1,2)$. Superparamagnetic iron oxide nanoparticles (SPIONs) have gained attention in medicine as a result of their excellent magnetic properties and low cytotoxicity (3). SPIONs are clinically approved as magnetic resonance imaging contrast agents and have also been used in hyperthermia treatment, chemotherapy and drug delivery (4-7). The biomedical applications of NPs require a complete understanding of their interaction with biological systems. The cytotoxicity of SPIONs remains unclear. For instance, carboxydextran-coated SPIONs did not affect the proliferation and viability of murine macrophages, but dextran-stabilized SPIONs could alter endothelial integrity and function $(8,9)$. Therefore, it is necessary to further assess the biological toxicity of these NPs. The accumulation of iron oxide NPs and release of free iron from the magnetite core may damage iron homeostasis in cells, resulting in inflammation, DNA damage or other toxin responses $(10,11)$. Furthermore, mitogen-activated protein kinases (MAPK) are induced in cells following exposure to NPs (12).

It is well accepted that NPs can deliberately access the vascular system via injection in the form of nano-medicine (13). Monocytes are the portal of NPs into the human body; they develop into macrophages or dendritic cells and are also involved in various diseases and tissue homeostasis (14). Although certain studies have evaluated the toxic effects of iron oxide NPs (15-17), the limited immune toxicity data and its underlying signaling mechanism require further investigation. It is preferable to select human primary cells for studying the bio-safety of NPs, as they are closer to the in vivo condition than non-human cells or immortalized cell lines (18). In the present study, therefore, the effects of Dex-SPIONs on certain key activities of human primary monocyte cells, including cell uptake, viability, pro-inflammatory cytokines (IL-1 $\beta$ and TNF- $\alpha$ ) and the potential signaling pathways were focused on.

\section{Materials and methods}

Characterization of Dex-SPIONs. Dex-SPIONs were synthesized following a previously described method (19). Briefly, a mixture of $2.508 \mathrm{~g}$ dextran T70 (Mw: 70 kDa, Sigma-Aldrich; Merck KGaA, Darmstadt, Germany) and $3.044 \mathrm{~g}$ iron 
(III) chloride hexahydrate (Shanghai Aladdin Bio-Chem Technology Co., Ltd., Shanghai, China) was dissolved in $20 \mathrm{ml}$ deionized water and placed in a three-neck flask equipped with a mechanical stirrer. A freshly prepared aqueous solution containing $1.27 \mathrm{~g}$ of ferrous chloride tetrahydrate (Shanghai Aladdin Bio-Chem Technology Co., Ltd.) dissolved in $2 \mathrm{ml}$ deionized water was added to the mixture above. While being rapidly stirred, $20 \mathrm{ml} \mathrm{7.5 \%} \mathrm{ammonium} \mathrm{hydroxide} \mathrm{solution} \mathrm{was}$ added into the mixture under argon protection. Subsequently, the suspension was heated to $75^{\circ} \mathrm{C}$ and maintained at this temperature for $30 \mathrm{~min}$ while stirring constantly. The black suspension was cooled and centrifuged at a speed of $400 \mathrm{x} \mathrm{g}$ for $15 \mathrm{~min}$ at $4^{\circ} \mathrm{C}$ to separate large particles. The ammonium chloride along with excess ammonia and dextran was removed by dialysis using a citrate buffer $(0.01 \mathrm{~mol} / \mathrm{l}$; Shanghai Aladdin Bio-Chem Technology Co., Ltd.). Characterization of Dex-SPIONs was performed using TEM (Jeol2100f; JEOL, Ltd., Tokyo, Japan). Dynamic light scattering was used to analyze the $\zeta$-potential and hydrodynamic size (Zeta Sizer, Malven Nano ZS90; Malvern Panalytical Ltd., Malvern, UK). The initial concentration of the NPs was determined by quantitative prussian blue assay.

Isolation of human monocyte cells. The present study was approved by the Institutional Review Board of the West China Second University Hospital of Sichuan University (Chengdu, China). Peripheral blood $(20 \mathrm{ml})$ mononuclear cells were obtained from human buffy coat residues (Chengdu Blood Center, Chengdu, China) using gradient centrifugation (400 x g for $30 \mathrm{~min}$ at $16^{\circ} \mathrm{C}$ ). Written informed consent was obtained from all patients $(n=15 ; 7$ females and 8 males; age, $38 \pm 3$ years) and samples were collected between October and December 2016). Human monocyte cells [Cluster of differentiation $(\mathrm{CD}) 14^{+}$cells] were purified using magnetic beads (Miltenyi Biotec GmbH, Bergisch Gladbach, Germany) according to the manufacturer's protocol. Cells with $>98 \%$ viability were obtained and the purity was $95-98 \%$ (data not shown), verified respectively by cytospin preparations and flow cytometry (BD Biosciences, Franklin Lakes, NJ, USA), as previously described (20).

Cell culture. Monocytes were seeded in 24-well plates in RPMI 1640 culture medium (Invitrogen; Thermo Fisher Scientific, Inc., Waltham, MA, USA) supplemented with $10 \%(\mathrm{v} / \mathrm{v})$ heat-inactivated fetal calf serum (FCS; Invitrogen; Thermo Fisher Scientific, Inc.) and antibiotics (1\% solution of penicillin $100 \mu \mathrm{g} / \mathrm{ml}$ and streptomycin $100 \mu \mathrm{g} / \mathrm{ml}$; Invitrogen; Thermo Fisher Scientific, Inc., Waltham, MA, USA) and incubated at $37^{\circ} \mathrm{C}, 5 \%(\mathrm{v} / \mathrm{v}) \mathrm{CO}_{2}$, and $95 \%$ relative humidity for $1 \mathrm{~h}$ (to allow enough time for attachment of monocytes). The medium was discarded following adhesion of the cells to the plate. Dex-SPIONs were mixed with RPMI 1640 medium \#at a concentration of $13.2 \mathrm{mg} / \mathrm{ml}$ to form the stock concentration from which the working concentration was derived. Subsequently, the cells were incubated with Dex-SPIONs (20 or $100 \mu \mathrm{g} / \mathrm{ml}$ ) in fresh pre-warmed medium for $24 \mathrm{~h}$.

Transmission electron microscopy (TEM). Following $24 \mathrm{~h}$ of incubation, cells were collected for TEM analysis as previously described (21). Briefly, monocyte cells were washed thrice with PBS and fixed with 2.5\% glutaraldehyde (Sigma-Aldrich; Merck $\mathrm{KGaA}$ ) in PBS at $4^{\circ} \mathrm{C}$ overnight. The fixed cells were dehydrated and subsequently embedded with a layer of Spurr epoxy resin at $60^{\circ} \mathrm{C}$ for $24 \mathrm{~h}$ (Polysciences Inc., Warrington, PA, USA). Ultrathin sections $(60-90 \mathrm{~nm})$ were collected on 200 mesh copper grids prior to staining with uranyl acetate and lead citrate (Polysciences, Inc.) for $30 \mathrm{~min}$ at room temperature. Samples were analyzed by TEM (Hitachi, Ltd., Tokyo, Japan; H600IV). Micrographs were processed using Adobe Photoshop CS5 software (Adobe Systems, Inc., San Jose, CA, USA).

Neutral red assays. Cells were seeded into 96-well plates $\left(1.5 \times 10^{5}\right.$ cells/well $)$ and incubated with Dex-SPIONs $(10-100 \mu \mathrm{g} / \mathrm{ml})$ for $24 \mathrm{~h}$ at $37^{\circ} \mathrm{C}$. Subsequently, the cells were treated with Neutral Red Cell Proliferation and Cytotoxicology Assay kit (Beyotime Institute of Biotechnology, Shanghai, China) following the manufacturer's protocol and the absorbance was measured at a wavelength of $540 \mathrm{~nm}$ using microplate reader (Bio-Rad Laboratories, Inc., Hercules, CA, USA).

Flow cytometry. Cells were collected and washed with PBS. Subsequently, cell suspensions $\left(5 \times 10^{5}\right.$ cells) were stained with anti-CD14 (1:100) in $100 \mu \mathrm{l} \mathrm{PBS}$ with 5\% FCS (cat no. 301829; Biolegend Inc., San Diego, CA, USA) for $30 \mathrm{~min}$ at room temperature. An annexin V-fluorescein isothiocyanate/propidium iodide apoptosis detection kit (Beijing Solarbio Science \& Technology, Co., Ltd., Beijing, China) was used according to the manufacturer's protocol. Cells were subsequently analyzed within $1 \mathrm{~h}$ by flow cytometry (BD Biosciences). Flow cytometric data were processed using FlowJo v.8.5.2 (Flowjo, LLC, Ashland, OR).

Quantification of cytokines. Cell supernatants were recovered following $24 \mathrm{~h}$ of incubation. The levels of interleukin (IL)-1 $\beta$ (cat. no. P01584) and tumor necrosis factor (TNF)- $\alpha$ (cat. no. P01375) were evaluated using commercially available human ELISA kits (RayBiotech, Inc., Norcross, GA, USA) according to the manufacturer's protocol and the absorbance was measured at $450 \mathrm{~nm}$ using a microplate reader (Bio-Rad Laboratories, Inc.). Lipopolysaccharide (LPS; $1 \mu \mathrm{g} / \mathrm{ml}$; Merck $\mathrm{KGaA}$ ) was used as a positive control.

To further assess the effects of Dex-SPIONs on the MAPK pathway, cells were incubated with the MAPK inhibitors SB 203580 (for p38; Tocris Bioscience, Bristol, UK), SP 600125 (for JNK; Absin Bioscience Inc., Shanghai, China) and PD98059 [for extracellular regulated kinase (ERK)1/2; Cell Signaling Technology, Inc., Danvers, MA, USA; $10 \mu \mathrm{M}$ in all cases] for $1 \mathrm{~h}$ at $37^{\circ} \mathrm{C}$ prior to the addition of Dex-SPIONs. The cells were cultured for $24 \mathrm{~h}$ at $37^{\circ} \mathrm{C}$ and cell supernatants were collected to analyze cytokine concentrations.

Western blot analysis. Cells were seeded in 24-well plates $\left(1.2 \times 10^{6}\right.$ cells/well) in the presence of Dex-SPIONs $(100 \mu \mathrm{g} / \mathrm{ml})$ for $24 \mathrm{~h}$. Cells were harvested, pelleted (centrifugation at $300 \mathrm{x} \mathrm{g}$ for $5 \mathrm{~min}$ at room temperature) and lysed by adding Western-IP lysis buffer (Beyotime Institute of Biotechnology). Protein concentrations were determined with a bicinchoninic acid protein assay. An equal amount of protein $(35 \mu \mathrm{g})$ for each 
sample was subjected to SDS-PAGE (10\% and $12 \%$ separation gels) and transferred onto polyvinylidene fluoride (PVDF) membranes. Membranes were subsequently blocked with 5\% non-fat dry milk for $1 \mathrm{~h}$ at room temperature and incubated with anti-GAPDH (1:1,000; cat. no. 97166; CST Biological Reagents Co., Ltd., Shanghai, China), anti-p38 (1:1,000; cat. no. 9212; CST Biological Reagents Co., Ltd.), anti-phosphorylated (p)-p38 (1:1,000; cat. no. 9211; CST Biological Reagents Co., Ltd.), anti-JNK (1:1,000; cat. no. 9252; CST Biological Reagents Co., Ltd.), anti-p-c-Jun N-terminal kinase 1 (JNK; 1:1,000; cat. no. 9251; CST Biological Reagents Co., Ltd.), anti-ERK (1:1,000; cat. no. 4695S; CST Biological Reagents Co., Ltd.) and anti-p-ERK (1:1,000; cat. no. 9101S; CST Biological Reagents Co., Ltd.) overnight at $4^{\circ} \mathrm{C}$. The PVDF membranes were incubated with an appropriate horseradish peroxidase-conjugated secondary antibody (1:5,000; cat. no. AP132P; Merck KGaA) for $1 \mathrm{~h}$ at room temperature, then protein bands were visualized with a super signal chemiluminescence (ECL) kit (Beyotime Institute of Biotechnology). The densitometric analysis of western blot was performed using Chemi-Doc (Quantity One 4.6.8; Bio-Rad Laboratories, Inc.).

Statistical analysis. Results are presented as the mean \pm standard error of mean and the data conformed to Gaussian distribution. Statistical analyses were performed using SPSS 11.0 (SPSS Inc., Chicago, IL, USA). Significant differences were evaluated by one-way analysis of variance followed by Dunnett's post-hoc test (at least three experiments). $\mathrm{P}<0.05$ was considered to indicate a statistically significant difference.

\section{Results}

Characterization of Dex-SPIONs. The size of the Dex-SPIONs were first characterized prior to using them in the subsequent experiments. The mean sizes of the NPs were calculated using Adobe Photoshop CS5 following appropriate calibration. Dynamic light scattering was also used to analyze the $\zeta$-potential and hydrodynamic size. As demonstrated in Fig. 1, Dex-SPIONs were observed to be an average of $7 \mathrm{~nm}$ in diameter and demonstrated to be spherical in shape. Furthermore, Dex-SPIONs exhibited a negative potential $(-11 \mathrm{mV})$ in cell culture medium and the hydrodynamic size was $\sim 63 \mathrm{~nm}$ (Table I). SPIONs are divided into three main categories based on their hydrodynamic diameter; this NP belongs to the standard size SPIONs, which have an overall diameter of 50-150 $\mathrm{nm}(22)$.

Cellular uptake and localization of Dex-SPIONs. To follow the intracellular localization and internalization of Dex-SPIONs, TEM was used to observe the cellular response (Fig. 2). Monocytes treated with Dex-SPIONs $(100 \mu \mathrm{g} / \mathrm{ml})$ exhibited vacuoles with highly electron-dense Dex-SPIONs (Fig. 2B and D) compared with the control group (Fig. 2A and C). Following careful observation of the TEM images, Dex-SPIONs were demonstrated to either be engulfed by monocytes in phagosomes or freed in the cytoplasm (Fig. 2B). There were bulky vacuoles present and a number of pseudopodia from the cell membrane (Fig. 2D). Furthermore, side-scatter light of flow cytometry representing cell

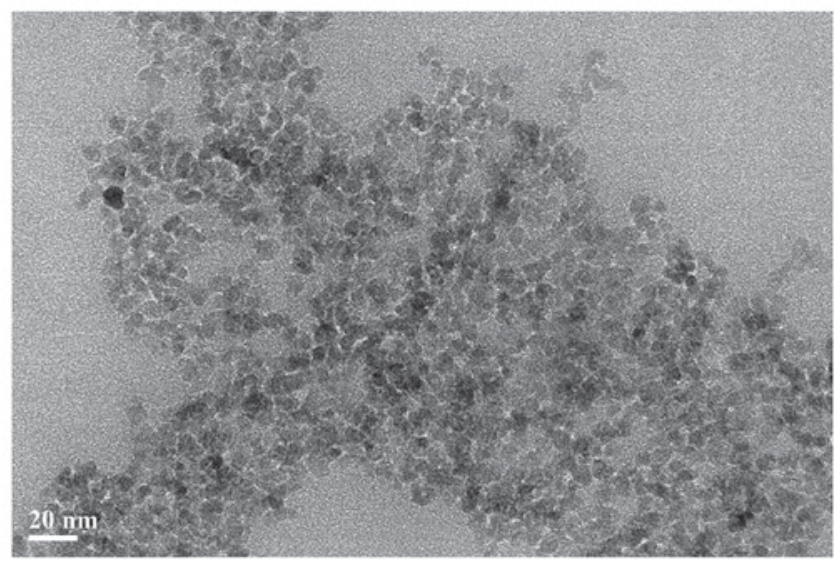

Figure 1. Transmission electron microscopy of dextran coated-superparamagnetic iron oxide nanoparticle (scale bar, $20 \mathrm{~nm}$ ).

granularity was increased following Dex-SPIONs exposure and it also indicated that Dex-SPIONs were phagocytosed by monocytes (Fig. 2E). These results definitively demonstrated an interaction between these NPs and cells.

Effect of Dex-SPIONs on the cell viability. In order to determine whether the Dex-SPIONs that enter the cells evoke a cell viability response, the number of Annexin $\mathrm{V}^{+} / \mathrm{PI}^{+}$(apoptotic or dead) or Annexin $\mathrm{V}^{-} / \mathrm{PI}^{-}$(live) cells following Dex-SPIONs exposure at concentrations ranging from 10 to $100 \mu \mathrm{g} / \mathrm{ml}$ was determined. It was demonstrated that Dex-SPIONs exhibited no significant effects on cellular apoptosis and viability (Fig. 3A and B). In addition, cell viability was further analyzed by neutral red assays. As illustrated in Fig. 3C, Dex-SPIONs did not influence the viability of cell even at $100 \mu \mathrm{g} / \mathrm{ml}$ compared with the control group following $24 \mathrm{~h}$ of incubation.

Effect of Dex-SPIONs on pro-inflammatory cytokines production in human monocyte cells. To examine the activation of human monocyte cells, an ELISA was used to analyze relevant parameters. The expression level of IL-1 $\beta$ was significantly improved following Dex-SPIONs treatment in a concentration-dependent manner $(\mathrm{P}<0.05$ and $\mathrm{P}<0.01$; Fig. $4 \mathrm{~A})$. Dex-SPIONs treatment significantly increased the production of TNF- $\alpha$ in the group at $100 \mu \mathrm{g} / \mathrm{ml}(\mathrm{P}<0.01$; Fig. 4B). In addition, dextran did not affect the secretion of cytokines in cells (data not shown). LPS $(1 \mu \mathrm{g} / \mathrm{ml})$ was used as a positive control.

Effect of Dex-SPIONs on the MAPK signaling pathway in human monocyte cells. To further investigate the underlying signaling pathway of the activation of monocytes induced by Dex-SPIONs, MAPK p38, JNK, ERK proteins and their respective inhibitors were used. Dex-SPIONs treatment significantly increased the phosphorylation levels of MAPK p38, JNK and ERK compared with the control group $(\mathrm{P}<0.05$; Fig. 5A-C). IL-1 $\beta$ production only decreased significantly in the presence of SP 600125 (JNK inhibitor) or PD 98059 (ERK inhibitor; both $\mathrm{P}<0.01$; Fig. 5D). However, co-treatment of Dex-SPIONs with inhibitors significantly reduced the expression level of TNF- $\alpha(\mathrm{P}<0.05$; Fig. 5E). Additionally, the inhibitors themselves did not modify cytokine expression in cells (data not shown). 
Table I. Characterization of the particle parameters of Dex-SPION.

\begin{tabular}{lccc}
\hline Nanoparticle & Hydrodynamic size $(\mathrm{nm})$ & $\xi$-potential $(\mathrm{mV})$ & Initial concentration $(\mathrm{mg} / \mathrm{ml})$ \\
\hline Dex-SPION & 62.8 & -11 & 13.2
\end{tabular}

Dex-SPION, dextran coated-superparamagnetic iron oxide nanoparticle.
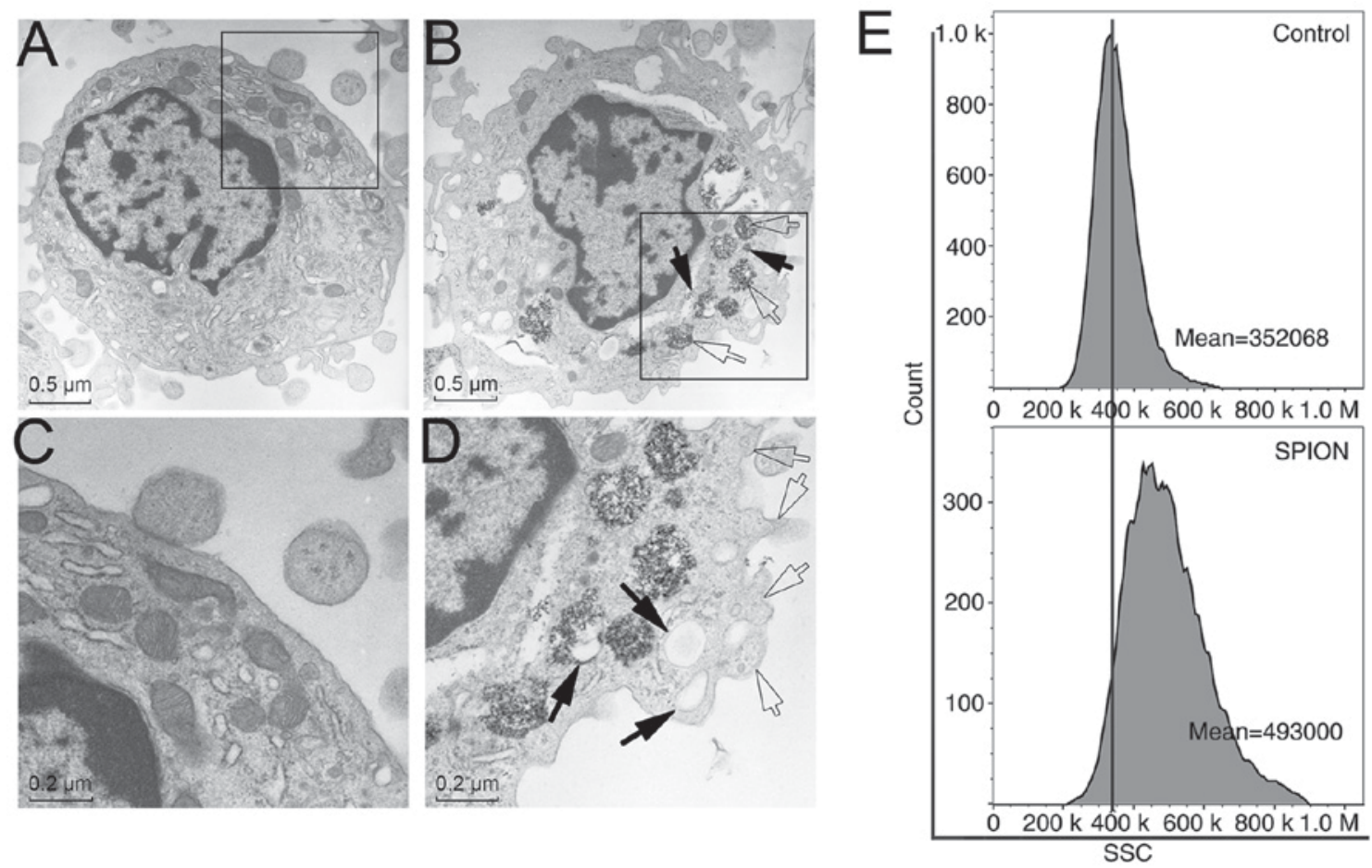

Figure 2. Cellular uptake of Dex-SPION. Cells were incubated with Dex-SPION $(100 \mu \mathrm{g} / \mathrm{ml})$ for $24 \mathrm{~h}$. The cells were collected and examined by transmission electron microscopy. (A) Human monocyte cells without any treatment. (B) Human monocyte cells treated with Dex-SPION (scale bar: $0.5 \mu$ m). Dex-SPIONs were either in phagosomes (black arrows) or free in the cytoplasm (transparent arrows). (C) Higher magnification of cells in black boxed areas (scale bar: $0.2 \mu \mathrm{m}$ ) in A and (D) in B. Large vacuoles (black arrows) and pseudopodia (transparent arrows) of the cell membrane. (E) Cells were collected and detected by flow cytometry. Mean values represent mean fluorescence intensities of side-scatter light. Dex-SPION, dextran-coated superparamagnetic iron oxide nanoparticle.

\section{Discussion}

SPIONs have enormous potential for biomedical applications, but there remains a gap in the knowledge about their reactions with the human immune system. In the present study, Dex-SPIONs were demonstrated to be uptaken by human monocyte cells and the cells were subsequently activated through the MAPK signaling pathway. To a certain extent, the results of the present study offered a better understanding and more convincing experimental evidence for the issue of SPIONs safety.

Monocytes are crucial innate immune cells, professional phagocytes whose main function is to recognize, ingest and degrade foreign invaders including bacteria and NPs (23). The results of the present study demonstrated that Dex-SPIONs were internalized by human monocyte cells and located in phagosomes or freed in the cytoplasm, which is similar to other studies $(24,25)$. Certain spherical vesicles resembling lysosomes fully packed with Dex-SPIONs in the cytoplasm were observed. It has been demonstrated that most endocytic routes of NPs are concentrated in the lysosomes, which leads to lysosomes being the common site for accumulation of NPs (26).

It is well documented that the cellular uptake of NPs have a crucial role in influencing certain cellular functions, including cell viability and inflammation (27). Whether SPIONs are cytotoxic or not is controversial. Certain studies have demonstrated SPIONs to be safe, while others have demonstrated SPIONs toxicity $(18,28,29)$. It may depend on the size of the NPs, any modifications or cell types studied. Coating is vital to stabilize SPIONs as it can decrease the toxicity of SPIONs by preventing aggregation and leakage of free iron ions. Dextran has excellent biocompatibility and has been used in the clinic for a long time, but it has been reported to modify cell-cell interaction and cell viability (30). However, the results of the present study demonstrated that dextran had no impact on the production of cytokines. Furthermore, Dex-SPIONs showed no cytotoxicity and can't increase in apoptosis in human monocyte cells. These results indicated that these NPs have a good biocompatibility. 

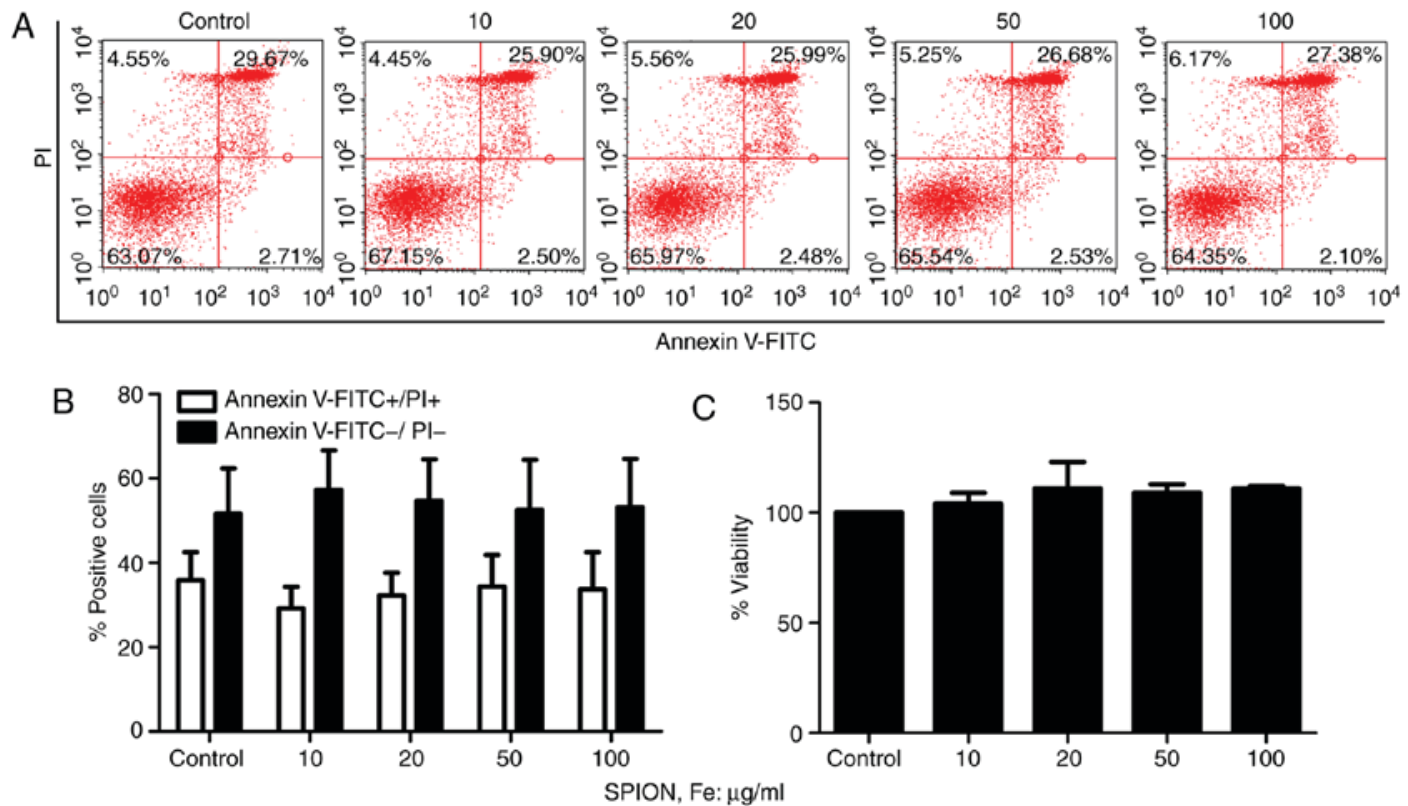

Figure 3. Effect of Dex-SPION on cell viability. (A) Cells were treated with Dex-SPION (10-100 $\mu \mathrm{g} / \mathrm{ml}$ ) for $24 \mathrm{~h}$, stained with Annexin V-FITC/PI and detected by flow cytometry. (B) Graphical representation of these results. (C) Cell viability was analyzed using a neutral red assay. Data were presented as the mean \pm standard deviation, $\mathrm{n}=3$. Dex-SPION, dextran coated-superparamagnetic iron oxide nanoparticle; FITC, fluorescein isothiocyanate; PI, propidium iodide.

A

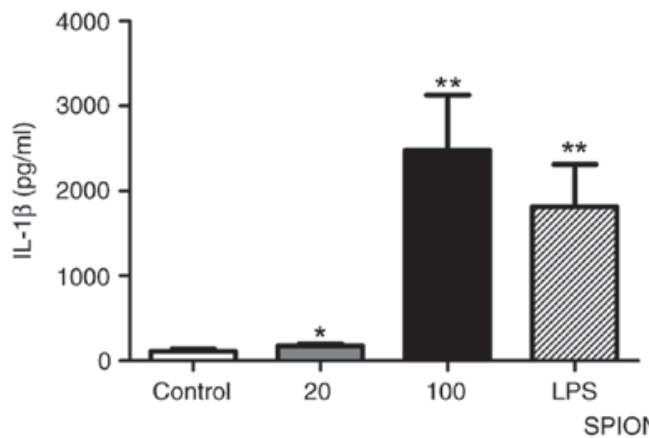

B

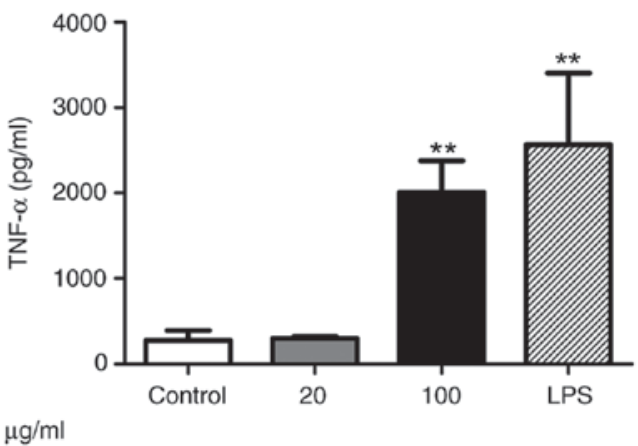

Figure 4. Proinflammatory cytokines production induced by Dex-SPION. Cells were incubated with Dex-SPION for 24 h. (A) The level of IL-1 1 . (B) The level of TNF-a. Data were presented as the mean \pm standard deviation, $\mathrm{n}=3 .{ }^{*} \mathrm{P}<0.05,{ }^{* *} \mathrm{P}<0.01 \mathrm{vs}$. the control; LPS $(1 \mu \mathrm{g} / \mathrm{ml})$, used as positive control. IL, interleukin; TNF, tumor necrosis factor; LPS, lipopolysaccharide.

Bulky vacuoles and a number of pseudopodia of the cell membrane were observed, indicating the potential activation of human monocyte cells following Dex-SPIONs exposure. When undergoing activation, monocytes can secrete various pro-inflammatory cytokines, which have an important role in immune and inflammatory responses. Of these cytokines, IL- $1 \beta$ and TNF- $\alpha$ are the commonly used markers of monocytes activation (31). To further evaluate the activation of cells, the expression levels of IL-1 $\beta$ and TNF- $\alpha$ were analyzed. The production of IL-1 $\beta$ and TNF- $\alpha$ were enhanced following Dex-SPIONs treatment. In one case, bare-iron oxide NPs increased the secretion of TNF- $\alpha$ as well as the generation of reactive oxygen species in RAW 264.7 cells (32). It is noteworthy that cytokines, in particular pro-inflammatory cytokines can be useful tools in evaluating immunotoxicity of NPs (33). According to the literature and the results of the present study, it was inferred that Dex-SPIONs may induce immunotoxicity of monocytes by enhancing the production of pro-inflammatory cytokines, but this conclusion requires further testing in vivo. p38, JNK and ERK, which are all the members of the MAPK family, are involved in a number of functions, including inflammation, cytokine production, transcriptional and apoptosis (34). In order to prove the potential signaling mechanism of cell activation, the phosphorylation levels of p38, JNK and ERK were measured. It is well documented that the MAPK signaling pathway can be induced in response to a diverse range of extracellular stresses including chemicals and cytokines $(35,36)$. Among these stresses, certain studies have reported that NPs can induce MAPK pathway activation, such as $\mathrm{ZnO}$ and $\mathrm{CuO}$ (37,38). Recently, Couto et al (39) demonstrated that iron oxide NPs could cause cytokine secretion and that the activation of MAPK p38 and JNK are involved in this effect. In the present study, Dex-SPIONs were verified to increase the expression levels of p-p38, p-JNK and p-ERK. Furthermore, MAPK inhibitors also inhibited the production of pro-inflammatory cytokines (IL-1 $\beta$ and TNF- $\alpha$ ). Based on these results, it was hypothesized that iron oxide NPs-caused inflammatory responses that were associated with the MAPK 
A

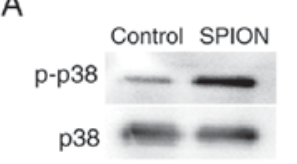

C
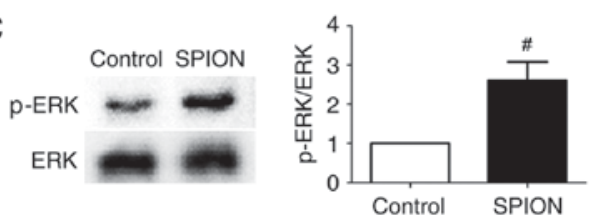

E
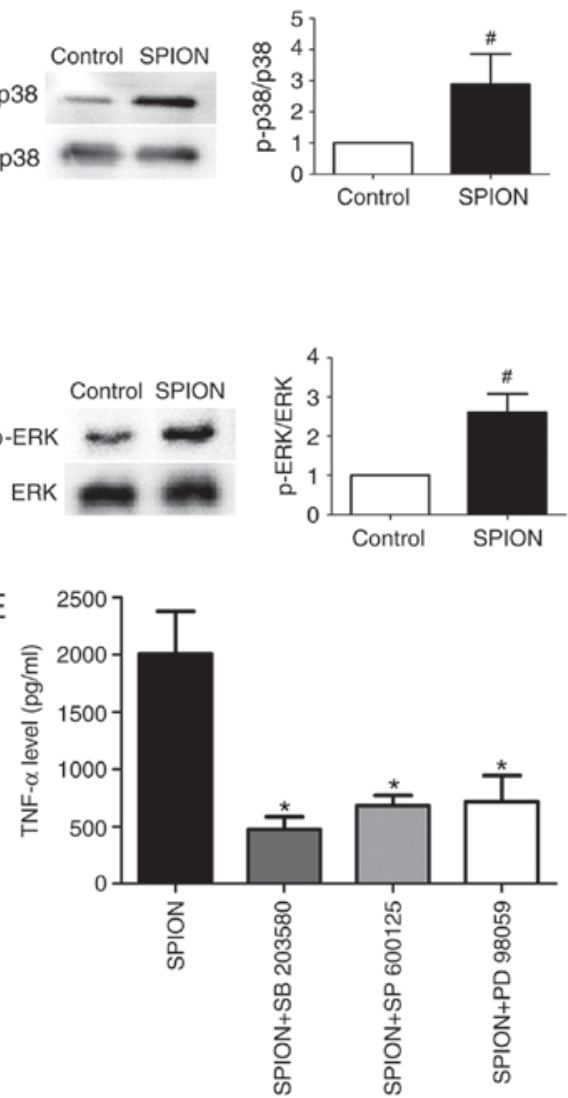

B
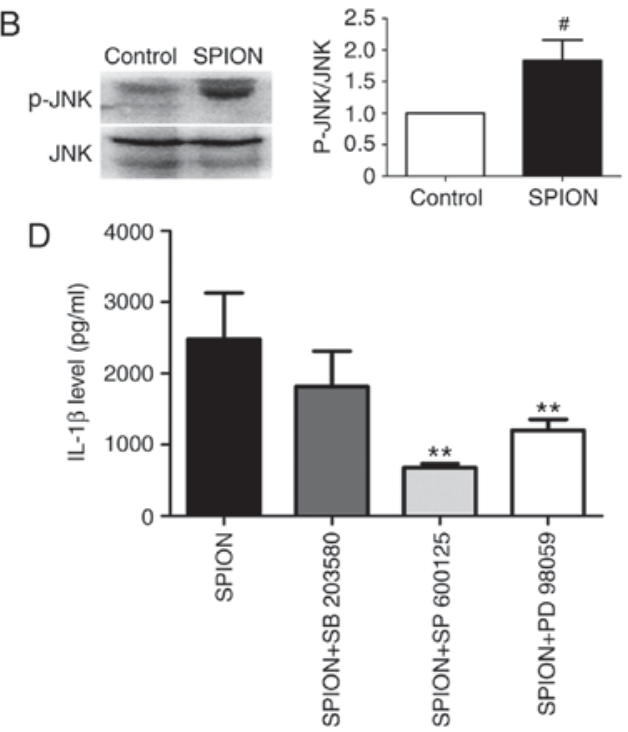

Figure 5. Dex-SPION induced the activation of MAPK p-p38, p-JNK and p-ERK in human monocyte cells. Monocytes were incubated with Dex-SPION $(100 \mu \mathrm{g} / \mathrm{ml})$ for $24 \mathrm{~h}$ or cells were treated with the MAPK inhibitors SB 203580 (for p38), SP 600125 (for JNK) and PD98059 (for ERK1/2; $10 \mu \mathrm{M}$ in all cases) for $1 \mathrm{~h}$ prior to the addition of Dex-SPION. Cells were subsequently prepared for western blotting and ELISA analyses. (A) p-p38/p38 expression. (B) p-JNK/JNK expression. (C) p-ERK/ERK expression. (D) The expression level of IL-1 $\beta$. (E) The expression level of TNF- $\alpha$. Data were presented as mean \pm standard deviation, $\mathrm{n}=3 .{ }^{*} \mathrm{P}<0.05$ vs. control; ${ }^{*} \mathrm{P}<0.05,{ }^{* *} \mathrm{P}<0.01$ vs SPION. IL, interleukin; TNF, tumor necrosis factor; ERK, extracellular signal regulated kinase; p-JNK, phosphorylated c-Jun N-terminal kinase 1; MAPK, mitogen-associated protein kinase; Dex-SPION, dextran coated-superparamagnetic iron oxide nanoparticle.

signaling pathway. The data from the present study demonstrated that there is an interaction between human monocyte cells and Dex-SPIONs, and this should be considered when deciding their various applications in the biomedical field. Future studies in animal models should enhance understanding of the health effects of these nanoparticles and may guide the risk assessment of their applications.

In conclusion, it demonstrated that Dex-SPIONs were engulfed by human monocyte cells and displayed the ability to activate monocytes via the induction of the formation of pseudopodia and the production of pro-inflammatory cytokines. In addition, these inflammatory responses possibly depended on the activation of MAPK signaling pathway.

\section{Acknowledgements}

Not applicable.

\section{Funding}

The present study was financially supported by the National Natural Science Foundation of China (grant no. 81471848) and the National Key Basic Research Program of Chain (grant no. 2013CB933903).

\section{Availability of data and materials}

The analyzed data sets generated during the study are available from the corresponding author on reasonable request.

\section{Authors' contributions}

QW designed the study and performed experiments. TM and TF performed the western blot analysis. CY performed the flow cytometry analysis. YG provided the nanoparticles, directed the project and interpreted the data. HL supervised the project and contributed to the study design. QW and YG wrote the paper. All authors discussed the results and contributed to the manuscript.

\section{Ethics approval and consent to participate}

The present study was approved by the Institutional Review Board of the West China Second University Hospital of Sichuan University (Chengdu, China). Written informed consent was obtained.

\section{Consent for publication}

Not applicable. 


\section{Competing interests}

The authors declare that they have no competing interests.

\section{References}

1. Gade A, Ingle A, Whiteley C and Rai M: Mycogenic meta nanoparticles: Progress and application. Biothchnol Lett 32 593-600, 2010

2. Jha RK, Jha PK, Chaudhury K, Rana SV and Guha SK: An emerging interface between life science and nanotechnology: Present status and prospects of reproductive healthcare aide by nano-biotechnology. Nano Rev 26: 5, 2014.

3. Jin R, Lin B, Li D and Ai H: Superparamagnetic iron oxide nanoparticles for MR imaging and therapy: Design considerations and clinical applications. Curr Opin Pharmacol 18: 18-27, 2014.

4. Hadjipanayis CG, Bonder MJ, Balakrishnan S, Wang X, Mao H and Hadjipanayis GC: Metallic iron nanoparticles for MRI contrast enhancement and local hyperthermia. Small 4: 1925-1929, 2008.

5. Mahmoudi M, Hosseinkhani H, Hosseinkani M, Boutry S, Simchi A, Journeay WS, Subramani K and Laurent S: Magnetic resonance imaging tracking of stem cells in vivo using iron oxide nanoparticles as a tool for the advancement of clinical regenerative medicine. Chem Rev 111: 253-280, 2011

6. Mahmoudi M, Sant S, Wang B, Laurent S and Sen T: Superparamagnetic iron oxide nanoparticles (SPIONs): Development, surface modification and applications in chemotherapy. Adv Drug Deliv Rev 63: 24-46, 2011.

7. Sun C, Lee JS amd Zhang M: Magnetic nanoparticles in MR imaging and drug delivery. Adv Drug Deliv Rev 60: 1252-1265, 2008

8. Hsiao JK, Chu HH, Wang YH, Lai CW, Chou PT, Hsieh ST, Wang JL and Liu HM: Macrophage physiology function after superparamagnetic iron oxide labeling. NMR Biomed 21 820-829, 2008.

9. Astanina K, Simon Y, Cavelius C, Petry S, Kraegeloh A and Kiemer AK: Superparamagnetic iron oxide nanoparticles impair endothelial integrity and inhibit nitric oxide production. Acta Biomater 10: 4896-4911, 2014.

10. Liu Y and Wang J: Effects of DMSA-coated $\mathrm{Fe}_{3} \mathrm{O}_{4}$ nanoparticles on the transcription of gens related to iron and osmosis homeostasis. Toxicol Sci 131: 521-536, 2013

11. Murray AR, Kisin E, Inman A, Young SH, Muhammed M, Burks T, Uheida A, Tkach A, Waltz M, Castranova V, et al: Oxidative stress and dermal toxicity of iron oxide nanoparticles in vitro. Cell Biochem Biophys 67: 461-476, 2013.

12. Wang Q, Chen B, Cao M, Sun J, Wu H, Zhao P, Xing J, Yang Y, Zhang X, Ji M and Gu N: Response of MAPK pathway to iron oxide nanoparticles in vitro treatment promotes osteogenic differentiation of hBMSCs. Biomaterials 86: 11-20, 2016.

13. Donaldson K, Duffin R, Langrish JP, Miller MR, Mills NL, Poland CA, Raftis J, Shah A, Shaw CA and Newby DE: Nanoparticles and the cardiovascular system: A critical review. Nanomedicine (Lond) 8: 403-423, 2013.

14. Robbins CS and Swirski FK: The roles of monocyte subsets in steady state and inflammation. Cell Mol Life Sci 67: 2685-2693, 2010 .

15. Szalay B, Tátrai E, Nyírő G, Vezér T and Dura G: Potential toxic effects of iron oxide nanoparticles in in vivo and in vitro experiments. J Appl Toxicol 32: 446-453, 2012.

16. Khan Ml, Mohammad A, Patil G, Nagvi SA, Chauhan LK and Ahmad I: Induction ROS, mitochondrial damage and autophagy in lung epithelial cancer cells by iron oxide nanoparticles. Biomaterials 33: 1477-1488, 2012.

17. Wu X, Tan Y, Mao H and Zhang M: Toxic effects of iron oxide nanoparticles on human umbilical vein endothelial cells. Int J Nanomedicine 5: 385-399, 2010.

18. Kunzmann A, Andersson B, Thurnherr T, Krug H, Scheynius A and Fadeel B: Toxicology of engineered nanomaterials: Focus on biocompatibility, biodistribution, biodegradation. Biochim Biophys Acta 1810: 361-373, 2011.
19. Hong RY, Feng B, Chen LL, Liu GH, Li HZ, Zheng Y and Wei DG: Synthesis, characterization and MRI application of dextran-coated $\mathrm{Fe}_{3} \mathrm{O}_{4}$ magnetic nanoparticles. Bio Eng J 42: 290-300, 2008

20. Xing Y and Hogguist KA: Isolation, identification, and purification of murine thymic epithelial cells. J Vis Exp 90: e51780, 2014.

21. Bachmann S, Schlichting U, Geist B, Mutig K, Petsch T, Bacic D, Wagner CA, Kaissling B, Biber J, Murer H and Willnow TE: Kidney-specific inactivation of the megalin gene impairs trafficking of renal inorganic sodium phosphate cotransporter (NaPi-lla). J Am Soc Nephrol 15: 892-900, 2004.

22. Singh N, Jenkins GJ, Asadi R and Doak SH: Potential toxicity of superparamagnetic iron oxide nanoparticles (SPION). Nano Rev 1: 3402, 2010

23. Aderem A and Underhill DM: Mechanisms of phagocytosis in macrophages. Annu Rev Immunol 17: 593-623, 1999.

24. Monteiro-Riviere NA, Inman AO and Zhang LW: Limitations and relative utility of screening assays to assess engineered nanoparticle toxicity in a human cell line. Toxicol Appl Pharmacol 234: 222-235, 2009

25. Strehl C, Gaber T, Maurizi L, Hahne M, Rauch R, Hoff P, Häupl T, Hofmann-Amtenbrink M, Poole AR, Hofmann H and Buttgereit F: Effects of PVA coated nanoparticles on human immune cells. Int J Nanomedicine 10: 3429-3445, 2015.

26. Stern ST, Adiseshaiah PP and Crist RM: Autophagy and lysosomal dysfunction as emerging mechanisms of nanomaterial toxicity. Part Fibre Toxicol 9: 20, 2012.

27. Oh WK, Kim S, Choi M, Kim C, Jeong YS, Cho BR, Hahn JS and Jang J: Cellular uptake, cytotoxicity, and innate immune response of silica-titania hollow nanoparticles based on size and surface functionality. ACS Nano 4: 5301-5313, 2010.

28. Thomsen LB, Linemann T, Pondman KM, Lichota J, Kim KS, Pieters RJ, Visser GM and Moos T: Uptake and transport of superparamagnetic iron oxide nanoparticles through human brain capillary endothelial cells. ACS Chem Neurosci 4: 1352-1360, 2013.

29. Peng M, Li H, Luo Z, Kong J, Wan Y, Zhang Q, Niu H, Vermorken A, Ven de Ven W, Chen C, et al: Dectran-coated superparamagnetic nanoparticles as potential cancer drug carriers in vivo. Nanoscale 7: 11155-11162, 2015.

30. Rouleau L, Rossi J and Leask RL: Concentration and time effects of dextran expouse on endothelial cell viability, attachment, and inflammatory marker expression in vitro. Ann Biomed Eng 38: $1451-1462,2010$

31. Gordon S: Alternative activation of macrophages. Nat Rev Immunol 3: 23-35, 2003

32. Park EJ, Umh HN, Kim SW, Cho MH, Kim JH and Kim Y: ERK pathway is activated in bare-FeNPs-induced autophagy. Arch Toxicol 88: 323-336, 2014.

33. Elsabahy M and Wooley KL: Cytokine as biomarkers of nanoparticle immunotoxicity. Chem Soc Rev 42: 5552-5576, 2013.

34. Dong C, Davis RJ and Flavell RA: MAP kinases in immune response. Annu Rev Immunol 20: 55-72, 2002.

35. Lee IC, Ko JW, Lee SM, Kim SH, Shin IS, Moon OS, Yoon WK, Kim HC and Kim JC: Time-course and molecular mechanism of hepatotoxicity induced by 1,3-dichloro-2-propanol in rats. Environ Toxicol Pharmacol 40: 191-198, 2015.

36. Zarubin T and Han J: Activation and signaling of p38 MAP kinase pathway. Cell Res 15: 11-18, 2005.

37. Ko JW, Park JW, Shin NR, Kim JH, Cho YK, Shin DH, Kim JC, Lee IC, Oh SR, Ahn KS and Shin IS: Copper oxide nanoparticle induces inflammatory response and mucus production via MAPK signaling in human bronchial epithelial cells. Environ. Toxicol Pharmacol 43: 21-26, 2016.

38. Yuan L, Wang Y, Wang J, Xiao H and Liu X: Additive effects of zinc oxide nanoparticles and isoorientin on apoptosis in human hepatoma cell line. Toxicol Lett 225: 294-304, 2014.

39. Couto D, Freitas M, Porto G, Lopez-Quintela MA, Rivas J, Freitas P, Carvalho F and Fernandes E: Polyacrylic acid-coated and non-coated iron oxide nanoparticles induce cytokine activation in human blood cells through TAK1, p38 MAPK and JNK pro-inflammatory pathways. Arch Toxicol 89: 1759-1769, 2015. 